where $a$ relates to the original disc, $b$ to the same disc after compressing it to about 10 per cent (the discs were rotated about an axis parallel to the $\mathrm{X}$-ray beam). The shift of the $\alpha_{1} \alpha_{2}$-lines amounts to about one sixth of their distance apart, corresponding to a decrease in spacing of about 0.04 per cent.

Wood observed that the rate of broadening of lines from different planes differed likewise ${ }^{3}$. A directional effect was also observed in our case in the sense that the degree of lattice distortion of a definite plane is dependent on the relative orientation of crystal lattice and direction of deformation ; for this experiment, strips of the recrystallised band were stretched by about 2 per cent parallel (Fig. 1c) and at $45^{\circ}$ (Fig. $1 d$ ) to the direction of rolling, that is, nearly parallel to a [100]- and a [110]-direction respectively. The severe distortion in the second case might perhaps be related to the fact, found for aluminium, that crystals stretehed in that direction exhibit an extremely pronounced recrystallisation power.

In conclusion, I wish to thank Mr. F. M. Jacobs for his help in taking the photographs.

Natuurkundig Laboratorium, W. G. Burgers.

der N. V. Philips',

Eindhoven, Holland.

1 W. A. Wood, Phil. Mag., 18, 495; 1934, 19, $219 ; 1935$.

2 W. G. Burgers and J. L.'Snoek, $Z$. Metallk., in press.

3 Compare also G. W. Brindley and F. W. Spiers, Proc. Leeds Phil. Soc., 3, 4; 1934. V. Caglioti and G. Sachs, Z. Phys., 74, 647; 1932 'W. G. Burgers, Pap. and Disc. Intern. Conf. Physics, London, 2, $139 ; 1934$.

\section{Lattice Parameters of Solid Solutions in Silver}

IN continuation of work on valency effects in alloys, I have recently measured the lattice parameters of the primary solid solutions in silver formed by the elements cadmium, indium, tin and antimony, which follow immediately after silver in the Periodic Table. This work has led to the discovery that in dilute solid-solutions of these elements, the alloys of the same equivalent composition have identical lattice parameters. By the term equivalent composition is meant the atomic percentage of the solute element multiplied by its valency, and the above relation implies that if the lattice parameters of the alloys are plotted against the equivalent compositions, the points for all of the four alloy-systems lie on a single curve. Alternatively, it may be said that the initial expansion of the silver lattice produced by one atom of the above elements is proportional to the valency.

The relation is thus of the same type as that previously found for the depression of freezing point of silver by the same elements, and may perhaps indicate an effect proportional to the repulsion between a solute and a solvent ion.

Old Chemistry Department,

\section{WULIAM HUMe-Rothery.}

University Museum,

Oxford.

May 24.

Dipole Moments of Ethyl and Phenyl Isocyanates

THE dipole moments ${ }^{1}$ and the Raman spectra ${ }^{2}$ indicate that the isothiocyanate group, $-\mathrm{N}=\mathrm{C}=\mathrm{S}$, is linear. The isocyanates are now found to resemble the isothiocyanates. The Raman spectra indicate that the group $-\mathrm{N}=\mathrm{C}=\mathrm{O}$ in the isocyanic esters is linear ${ }^{3}$, and this conclusion agrees with inferences drawn from the dipole moments.
Ethyl and phenyl isocyanates we find to have moments of $2 \cdot 81 D$ and $2 \cdot 28 D$ respectively. No other value for the ethyl compound is available, but the published results for phenyl isocyanate are $2.34 D$ at $18^{\circ}$ in benzene and $2.23 D$ at $25^{\circ}$ in carbon tetrachloride ${ }^{5}$, the mean being $2 \cdot 28 \mathrm{D}$.

The difference between the moments of the corresponding isothiocyanate and isocyanate gives the value of the excess of the $\mathrm{C}=\mathrm{S}$ over the $\mathrm{C}=\mathrm{O}$ moment. This difference deduced from other compounds is given below.

\begin{tabular}{|c|c|c|c|}
\hline $\begin{array}{l}\text { Ethyl isothiocyanate } \\
\text { Ethyl isocyanate }\end{array}$ & $\left.\begin{array}{l}3 \cdot 31 \\
2 \cdot 81\end{array}\right\} 0 \cdot 50$ & $\begin{array}{l}\text { Phenyl isothiocyanate } \\
\text { Phenyl isocyanate }\end{array}$ & $\left.\begin{array}{l}3 \cdot 00 \\
2 \cdot 28\end{array}\right\} 0$. \\
\hline $\begin{array}{l}\text { Thiobenzophenone } \\
\text { Benzophenone }\end{array}$ & $\left.\begin{array}{l}3 \cdot 37 \\
2 \cdot 95\end{array}\right\} 0 \cdot 42$ & $\begin{array}{l}\text { Dianisyl thioketone } \\
\text { Dianisyl ketone }\end{array}$ & $\left.\begin{array}{l}4 \cdot 44 \\
3 \cdot 90\end{array}\right\}$ \\
\hline
\end{tabular}

Bergmann has published two values of the moment of phenyl isothiocyanate, namely ${ }^{6}, 2 \cdot 76 \mathrm{D}$ and $^{4} 3.00 \mathrm{D}$, and it will be seen that the former value exceeds the moment of phenyl isocyanate by $0.48 \mathrm{D}$. The other figures are in satisfactory agreement with each other.

The solvent used in the present experiment was benzene, and measurements were at $20^{\circ}$. Ethyl isocyanate, prepared from potassium ethyl sulphate and potassium cyanate, was twice fractionated, dried by sodium sulphate and refractionated. The moment was measured immediately. The physical constants were: boiling point, $59 \cdot 8^{\circ} / 759 \mathrm{~mm}$. $d_{4}^{20} 0.9031 ; n_{D}^{20} 1 \cdot 3808$. Phenyl isocyanate from Kahlbaum was dried and fractionated : boiling point, $161 \cdot 7^{\circ} / 752 \mathrm{~mm}$.; $d_{4}^{20} 1 \cdot 0946 ; n_{D}^{20} 1 \cdot 5363$.

$\begin{array}{lccc} & P_{2 \infty} & P E & \mu \\ \text { Ethyl isocyanate } & 185 \text { c.c. } & 18 \cdot 3 \text { c.c. } & 2 \cdot 81 \mathrm{D} \\ \text { Phenyl isocyanate } & 144 \text { c.c. } & 33.9 \text { c.c. } & 2 \cdot 28 \mathrm{D}\end{array}$

The details of these results and those for analogous compounds will shortly be published.

J. R. Partington.

Queen Mary College,

E. G. Cowley

University of London. May 17.

${ }^{1}$ Hunter and Partington, J. Chem. Soc., 2825; 1932

2 Langseth, Nielson and Sørensen, Z. phys. Chem., B, 27, $100 ; 1934$.

3 Goubeau, Ber., 68, $912 ; 1935$.

- Eide and Hassel, Tids. Kjemi, 10, 93 ; 1930.

5 Sidgwick, Sutton and Thomas, J. Chem. Soc., 406 ; 1933.

- Z. phys. Chem., B, 10, 397; 1930 .

7 ibid., B, 17, 100; 1932.

\section{Interchange of Heavy Atoms in Organo-Metallic Compounds}

THE interchange of heavy atoms in organo-metallic compounds, reported by Mrs. Leigh-Smith and Dr. Richardson ${ }^{1}$, using the radioactive indicator method, is in line with work done by Hilpert and Grüttner ${ }^{2}$, who, however, found evidence of detachment of the organic radicals from the metal. They found that a reversible reaction took place between mercury diphenyl and metallie bismuth, with formation of a little diphenyl, at $250^{\circ}$ in hydrogen.

When working on alkyl bismuth compounds under the direction of Prof. W. J. Jones at Cardiff, I attempted to prepare mixed alkyl-bismuthines, and obtained results indicating some looseness of binding between the bismuth atom and the alkyl residues. On treating amyl bismuth dichloride with ethyl magnesium bromide, triethylbismuthine and tri$n$-amyl-bismuthine were obtained in addition to $n$-amyl-diethyl-bismuthine. Challenger ${ }^{3}$ obtained similar results with ethyl magnesium bromide and 